producing the conditions of the upper layer (the stratosphere) ?

This note is communicated with the permission of the director of the Meteorological Office.

Meteorological Office,

A. H. R. GoudIE

London, W.C.2.

Jan. 27. 1 A summary is given in the November and December 1949 Issues of

¿J. Meteorology, 6, No. 4 (1949).

\section{X-Ray Diffraction Pattern given by Bacterial Flagella}

A PRELIMINARy report has already been given ${ }^{1}$ on an X-ray diffraction study of bacterial flagella. The X-ray work was carried out in the Department of Biomolecular Structure of the University of Leeds, on flagellar preparations obtained from Uppsala. However, it has since proved useful to carry out some further X-ray work on the spot at Uppsala, and the following is a summary of the results so obtained.

The photographs were taken with copper $K \alpha$ radiation from a Philips tube running at $40 \mathrm{kV}$. and $18 \mathrm{~m}$.amp. The specimen-to-film distance was about $36 \mathrm{~mm}$., or $105 \mathrm{~mm}$. for the long spacings. The X-ray beam in the latter case had a divergence of 25', permitting the measurement of spacings up to about $150 \mathrm{~A}$.

The specimens used previously have been films made by drying pools of flagellar solutions on glass slides, and pseudo-fibre diagrams have been obtained. It has now been found possible to prepare actual fibres by rolling a thick flagellar paste between ground-glass plates. No difference has been observed in the diagrams at large angles; but the fibre diagrams show a sharp reflexion at $40 \mathrm{~A}$. which is not seen in the film diagrams. Possibly, therefore, there is a somewhat different packing of the flagella in the two cases, or the stress applied while forming the fibres brings about some slight modification of the flagellar structure.

X-ray studies of wet and dry hæmoglobin ${ }^{2}$ indicate that the molecules of this protein are anhydrous invariant units, with the water of hydration lying between. Bacterial flagella are very hygroscopic indeed, exposure for one or two days of a dry preparation to saturated humidity being sufficient to change it from a horny brittle mass to a thick glue. An X-ray comparison between a dry and wet specimen can be made by enclosing a flagellar fibre in a thin-walled glass capillary (giving only faint diffuse scattering) and sealing the capillary with water. In this way it has been shown that the wetting process alters the spacings, ranging from 4 to $40 \mathrm{~A}$., by only a few per cent at the most. Here also, then, a comparatively anhydrous invariant unit is suggested. A marked effect of the wetting is, however, a sharpening and increased resolution of the reflexions. The side-chain reflexion, which is rather diffuse in photographs of dry specimens, reveals three distinct components at $10 \cdot 6 \mathrm{~A},, 9 \cdot 3 \mathrm{~A}$. and $8 \cdot 2$ A., respectively.
A technique has been tried of stretching flagellar films by drying pools of sol on silicone rubber, then re-moistening and stretching the two together. This procedure was found to produce certain changes in the X-ray diagram, and in particular there appeared a very strong and sharp equatorial reflexion at $9 \cdot 3 \mathrm{~A}$., even with dry specimens.

Further details of these experiments will be given in the full account of the $\mathrm{X}$-ray investigations carried out at Leeds and Uppsala.

I am much indebted to P. H. Lindgren and Dr. E. Ribi for valuable help and advice in the X-ray technique.

Institute of Biochemistry,

University of Uppsala.

1 Astbury, W. T., and Weibull, C., Nature, 163, 280 (1948).

2 Boyes-Watson, J., Davidson, E., and Perutz, M. F., Proc. Roy. Soc., A, 191, 83 (1947).

\section{Electron-Microscopic Demonstration of a Membrane Structure Isolated from Nerve Tissue}

UsING a technique of preparation similar to the one used for the analysis of the ultra-structure of the outer segment of retinal rods ${ }^{1}$, it was possible to isolate a characteristic structure from the peripheral nerve tissue of the guinea pig. The sciatic nerve or motor roots of the spinal cord were fixed (24 hr.) in 2 per cent osmic acid, moderately fragmented by crushing between the ground-glass surfaces of a small glass joint by careful grinding and afterwards fragmented by sonic treatment using a frequency of $9 \mathrm{kc} . / \mathrm{s}$.

A mixture of sheets of varying thickness and fibrils, the latter obviously constituting the so-called neurotubules, was obtained. By differential centrifugation the thinner membranes could be separated from the fibrils, and almost pure preparations of the membranes resulted. The preparatory work was performed at $+4^{\circ} \mathrm{C}$. An $R C A$ electron microscope, type $E M U$, was used for the analysis.

The membranes are irregularly formed fragments of more extensive membranes of indefinite size, and the thicker membranes (Fig. 1) are composed of varying number of layers of thin membranes showing a uniform thickness (Fig. 2). The thickness is of the same order of magnitude as the unit disks of the retinal rod outer segments.

The mernbranes show a characteristic structure with dense spots arranged in larger or smaller areas scattered at random all over the membrane. On

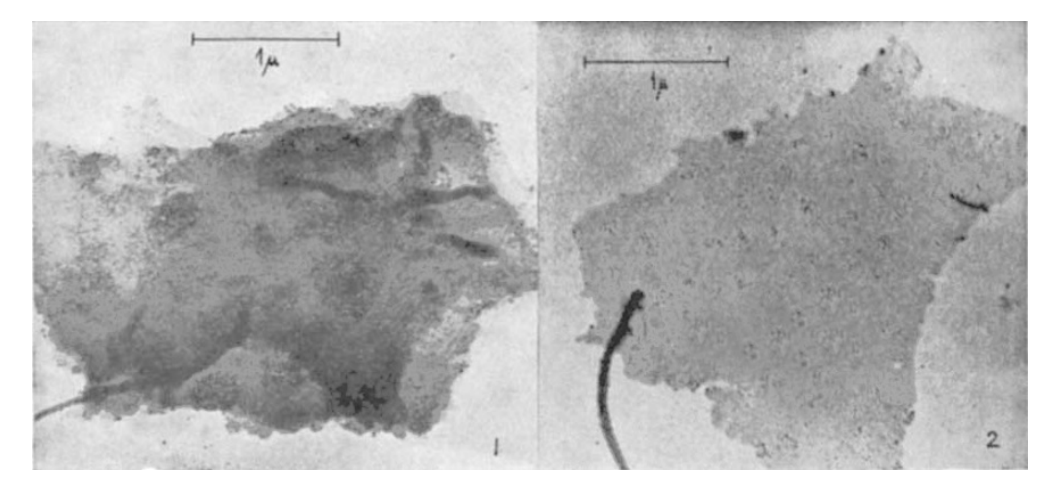

